\title{
Assessment of Medication Adherence in Psychiatric Patients in a Tertiary Care Hospital \\ Abubaker Siddiq ${ }^{1 *}$, Bharathi DR ${ }^{1}$, Himanshu Joshi ${ }^{2}$, Yogitha $\mathrm{A}^{1}$
}

${ }^{1}$ Department of Pharmacology and Pharmacy Practice, SJM College of Pharmacy, Chitradurga-577502, Karnataka, India

${ }^{2}$ College of Pharmacy, Graphic Era Hill University, Bhimtal Campus, Uttarakhand-263156, India

DOI: $10.36347 /$ sajp.2020.v09i06.001

| Received: 15.04.2020 | Accepted: 27.04.2020 | Published: 06.06.2020

*Corresponding author: Dr. Abubaker Siddiq

Abstract

Original Research Article

Medication adherence is a serious challenge for providers treating patients with many types of illness. Patients with acute conditions are more likely to be adherent than those with chronic disorders. In the Present study out of 201 patients enrolled, the medication adherence assessment was conducted in 59 patients who were selected based on the study criteria. The baseline score was taken and later the scores are taken at the First month and Second month. Among 59 patients the base line score was, 0 patients with score 0,9 patients with score 1,8 patients with score 2 , 12 patients with score 3,12 patients with score 4, 10 patients with score 5, 6 patients with score 6,2 patients with score 7 , 0 patients with score 8 .The first follow up score was 0 patients with score 0,14 patients with score 1,16 patients with score 2, 7 patients with score 3,14 patients with score 4, 6 patients with score 5,2 patients with score 6,0 patients with score 7, 0 patients with score 8 . The second follow up score was 0 patients with score 0,21 patients with score 1 , 14 patients with score 2, 17 patients with score 3, 2 patients with score 4, 3 patients with score 5,2 patients with score 6,0 patients with score 7, 0 patients with score 8 . The p-value between the base line and $1^{\text {st }}$ follow up, $1^{\text {st }}$ follow up and $2^{\text {nd }}$ follow up, base line and $2^{\text {nd }}$ follow up shows 1.00 which shows no significance; but descriptively it can be observed that, the patients are getting adhered to their medication, as the patients are coming to the group of moderately adherent and highly adherent.

Keywords: Adherence, Psychiatric, Follow-up.

Copyright @ 2020: This is an open-access article distributed under the terms of the Creative Commons Attribution license which permits unrestricted use, distribution, and reproduction in any medium for non-commercial use (NonCommercial, or CC-BY-NC) provided the original author and source are credited.

\section{INTRODUCTION}

Mental health refers to a broad array of activities directly or indirectly related to the mental well-being [1]. The good news about the psychiatric illness is that the recovery is possible. Mental illness can affect persons of any age, race, religion and income [2]. Psychiatric out-patient setting is an ideal venue for screening, triage and assessing the psychiatric morbidity [3]. The patient on psychotropic drugs needs to take drug as prescribed and regular follow up is necessary to regulate long term therapy [4]. Adherence to a medication regimen involves behavioral change on the part of the patient. Compliance and behavioral changes are positively influenced by the patient's level and stability of family support, level of self-awareness about their health status, and the efficacy of treatment. Self-efficacy can also affect motivation and behaviour. Patients with a high degree of self-efficacy are more likely to be actively involved in developing and completing tasks related to a medical or treatment regimen [5]. Some patients do not follow the prescribed treatment because of various reasons. One of the major factors for re-hospitalization is found to be noncompliance in taking drugs. Noncompliance is a personal behaviour that deviates from health related advice given by health care professional [6]. So, there is a need to evaluate the drug adherence in psychiatric patients.

\section{MATERIALS \& METHODS}

A Prospective-Observational Study was conducted in the Out-Patients of Psychiatry Department of Basaveshwara Medical College \& Hospital, Chitradurga, which is a tertiary care hospital providing health care services. Moresky medication adherence scale was used in assessing the medication adherence in psychiatric outpatients. This study was approved by the Institutional Human Ethics Committee of S.J.M College of Pharmacy, Chitradurga (SJMCP/IEC/677B/2013-14 Date-14/11/2013). The study was conducted for a period of six months with the following study criteria. 


\section{Inclusion Criteria}

- Out patients attending psychiatric department

- $\quad$ Age group : 18-60 years

- Pregnancy \& Lactating mothers suffering from psychiatric illness

\section{Exclusion Criteria}

- All In-patients of psychiatry department

Patients who satisfy above study criteria were included into the study. The signed informed consent form by the patient or by their representatives was taken. Patient's demographic detail, medical diagnosis, therapeutic category were collected and was documented in a suitably designed data collection form.

\section{STATISTICAL ANALYSIS}

The data was entered in Microsoft Excel-2010 version and the results are analyzed using Statistical Package for Social Services (SPSS 19.0). Descriptive statistical methods were applied for analysis.

\section{RESULTS}

A total of 201 patients were enrolled in the study in which 59 patients were selected based on the criteria. The baseline score was taken and later the scores are taken at the First month and Second month. Among 59 patients the base line score was, 0 patients with score 0,9 patients with score 1,8 patients with score 2, 12 patients with score 3,12 patients with score 4, 10 patients with score 5,6 patients with score 6,2 patients with score 7,0 patients with score 8 .

The first follow up score was 0 patients with score 0,14 patients with score 1,16 patients with score 2, 7 patients with score 3,14 patients with score 4,6 patients with score 5,2 patients with score 6,0 patients with score 7,0 patients with score 8 .

The second follow up score was 0 patients with score 0,21 patients with score 1,14 patients with score 2, 17 patients with score 3,2 patients with score 4, 3 patients with score 5,2 patients with score 6,0 patients with score 7,0 patients with score 8 .

Statistically by applying student-t test, the Mean \pm SD of base line score, $1^{\text {st }}$ follow up and $2^{\text {nd }}$ follow up are $6.56 \pm 4.82,6.56 \pm 6.616,6.56 \pm 8.338$ respectively. The p-value between the base line and $1^{\text {st }}$ follow up, $1^{\text {st }}$ follow up and $2^{\text {nd }}$ follow up, base line and $2^{\text {nd }}$ follow up shows 1.00 which shows no significance; but descriptively it can be observed that, the patients are getting adhered to their medication, as the patients are coming to the group of moderately adherent and highly adherent. The results are depicted in Table 1 and 2.

Table-1: Distribution based on the Medication Adherence Scores

\begin{tabular}{|l|l|l|l|l|}
\hline Level of Adherence & Score & Base line & 1st Follow up & 2nd Follow up \\
\hline Highly Adherent & $\mathbf{0}$ & 0 & 0 & 0 \\
\hline \multirow{3}{*}{ Moderately Adherent } & $\mathbf{1}$ & 9 & 14 & 21 \\
\cline { 2 - 5 } & $\mathbf{2}$ & 8 & 16 & 14 \\
\hline \multirow{5}{*}{ Low Adherent } & $\mathbf{3}$ & 12 & 7 & 17 \\
\cline { 2 - 5 } & $\mathbf{4}$ & 12 & 14 & 2 \\
\cline { 2 - 5 } & $\mathbf{5}$ & 10 & 6 & 3 \\
\cline { 2 - 5 } & $\mathbf{6}$ & 6 & 2 & 2 \\
\cline { 2 - 5 } & $\mathbf{7}$ & 2 & 0 & 0 \\
\cline { 2 - 5 } & $\mathbf{8}$ & 0 & 0 & 0 \\
\hline
\end{tabular}

Table-2: Statistical Results of Medication Adherence Scores

\begin{tabular}{|l|l|l|l|l|l|l|l|}
\hline \multirow{2}{*}{ Pairs } & \multicolumn{2}{|l|}{ Paired Differences } & T & Df & \multirow{2}{*}{ Sig. } \\
\cline { 2 - 6 } & Mean & SD & \multicolumn{2}{|c|}{ 95\% CI of Difference } & & & \\
\cline { 2 - 8 } & & & Lower & Upper & & & \\
\hline Base line- $1^{\text {st }}$ Follow up & 0.00 & 4.387 & -3.373 & 3.373 & 0.000 & 8 & 1.00 \\
\hline $1^{\text {st }}$ Follow up $-2^{\text {nd }}$ Follow up & 0.00 & 6.185 & -4.754 & 4.754 & 0.000 & 8 & 1.00 \\
\hline Base line $-2^{\text {nd }}$ Follow up & 0.00 & 6.837 & -5.256 & 5.256 & 0.000 & 8 & 1.00 \\
\hline
\end{tabular}

\section{DISCUSSION}

Non-adherence to medication regimens is a serious problem. It has many serious effects on prognosis of the illness and overall effectiveness of health systems. Increasing the effectiveness of adherence interventions may have a far greater impact on the health of the population than any improvement in specific medical treatments [7]. In our study, the medication adherence assessment was performed through 8-point Morisky Medication Adherence Questionnaire. Among 59 patients, the patients with score 1 and 2 who are moderately adherent were 17 patients at the base line but 35 patients were moderately adherent at $2^{\text {nd }}$ month follow up. In a study conducted by Kousalya $\mathrm{K}$ et al., where the assessment of medication adherence in psychiatric patients were conducted in 200 patients, shows that $21.50 \%$ patients were compliant and $78.50 \%$ patients were noncomplaint, which was assessed by Drug Attitude 
Inventory [8]. The medication adherence assessment in psychiatric out patients conducted by Mahaye et al., shows that $12.6 \%$ patients were highly adherent, $50.6 \%$ patients were moderately adherent [9]. In our study, in the medication adherence assessment, descriptively it can observed that the number of patients getting moderately adhered was getting increased but there is no statistical significant difference between the baseline and $2^{\text {nd }}$ follow up; which may be due short duration of time and less sample size.

\section{CONCLUSION}

According to the analyzed results the conclusions made are Male patients are more prone to Psychiatric illness with age group of 18-40 years. The Improvement in the medication adherence is observed descriptively but not statistically.

\section{ACKNOWLEDGEMENTS}

The authors are thankful to the President \& management of SJM Vidyapeetha through the Principal of SJM College of Pharmacy, Chitradurga, Karnataka for providing necessary facilities to carry out this work. We are grateful to Clinical and non-clinical staff of Department of Psychiatry. The authors are also thankful to the patients who got enrolled in the study and provided the necessary information for the conduction of the study.

\section{REFERENCES}

1. WHO. World Health Organization [Internet]; 2010 [cited 2014 April 15]. Available from: http://www.who.int/topics/mental- health/en/

2. NAMI. Arlington: National Alliance On Mental Illness [Internet]; 1996-2013 [cited 2013 Dec 02]
Available

from

http://www.nami.org/template.cfm?section=about _mental_illness.

3. Jhanjee A, Kumar P, Shruti S, Bhatia MS. A Descriptive study of Referral Pattern in Department of Psychiatry of a Tertiary care hospital of North India. Delhi Psychiatry Journal, April 2011; 14(1):92-94.

4. Miller R. Bibliography of Medication Compliance. Psychiatry, 2002; 63 (12): 1121-8.

5. Al-Jumah KA, Qureshi NA. Impact of pharmacist interventions on patients' adherence to antidepressants and patient-reported outcomes: a systematic review. Patient Prefer Adherence. 2012;6:87-100.

6. Harmon RB, Tratnack SA. Teaching hospitalized patients with serious, persistent mental illness. Journal of psychosocial nursing and mental health services. 1992 Jul 1;30(7):33-6.

7. Barnwal A, Oza B, Patel V. Metabolic side effects of antipsychotic agents: a prospective study in a teaching hospital. NHL Journal of Medical Sciences. 2012 Jul;1(1):23-6.

8. Kousalya K, Vasantha J, Ponnudura R, Sumitkumar G, Ramalakshmi S, Saranya S, Reddy CU. Study on non-adherence and the effect of counselling in the pharmacological management of psychiatric patients. International Journal of Pharma and Bio Sciences. 2012;1:102-09.

9. Mahaye S, Mayime T, Nkosi S, Mahomed FN, Ntuli L, Pramlal J, Setlhabana O, Oosthuizen F. Medication adherence of psychiatric patients in an outpatient setting. African Journal of pharmacy and pharmacology. 2012 Mar 8;6(9):608-12. 